\title{
BMJ Open Imputing HbA1c from capillary blood glucose levels in patients with type 2 diabetes in Sri Lanka: a cross- sectional study
}

\author{
Monica Choo, ${ }^{1}$ Gregory E. Hoy, ${ }^{1,2}$ Sarah P. Dugan, ${ }^{1}$ Laura N. McEwen, ${ }^{3}$ \\ Naresh Gunaratnam, ${ }^{1,4,5}$ Jennifer Wyckoff, ${ }^{6}$ Thangarasa Jeevaraaj, ${ }^{7}$ \\ Arunachalam Saththiyaseelan, ${ }^{8}$ B. Ganeikabahu, ${ }^{9}$ Prasad Katulanda, ${ }^{10}$ \\ Ulysses Balis, ${ }^{11}$ William H. Herman, ${ }^{6,12}$ Anjan K. Saha (1) ${ }^{1,2}$
}

To cite: Choo M, Hoy GE, Dugan SP, et al. Imputing HbA1c from capillary blood glucose levels in patients with type 2 diabetes in Sri Lanka: a crosssectional study. BMJ Open 2020;10:e038148. doi:10.1136/ bmjopen-2020-038148

- Prepublication history and additional material for this paper are available online. To view these files, please visit the journal online (http://dx.doi. org/10.1136/bmjopen-2020038148).

MC and GEH are joint first authors.

WHH and AKS are joint senior authors.

Received 29 February 2020 Revised 19 May 2020 Accepted 16 June 2020

Check for updates

(c) Author(s) (or their employer(s)) 2020. Re-use permitted under CC BY-NC. No commercial re-use. See rights and permissions. Published by BMJ.

For numbered affiliations see end of article.

Correspondence to

Dr Anjan K. Saha;

aksaha@med.umich.edu

\section{ABSTRACT}

Objective To develop a population-specific methodology for estimating glycaemic control that optimises resource allocation for patients with diabetes in rural Sri Lanka. Design Cross-sectional study.

Setting Trincomalee, Sri Lanka.

Participants Patients with non-insulin-treated type 2 diabetes $(n=220)$ from three hospitals in Trincomalee, Sri Lanka.

Outcome measure Cross-validation was used to build and validate linear regression models to identify predictors of haemoglobin A1c (HbA1c). Validation of models that regress $\mathrm{HbA} 1 \mathrm{C}$ on known determinants of glycaemic control was thus the major outcome. These models were then used to devise an algorithm for categorising the patients based on estimated levels of glycaemic control. Results Time since last oral intake other than water and capillary blood glucose were the statistically significant predictors of $\mathrm{HbA1C}$ and thus included in the final models. In order to minimise type II error (misclassifying a high-risk individual as low-risk or moderate-risk), an algorithm for interpreting estimated glycaemic control was created. With this algorithm, $97.2 \%$ of the diabetic patients with $\mathrm{HbA} 1 \mathrm{c}$ $\geq 9.0 \%$ were correctly identified.

Conclusions Our calibrated algorithm represents a highly sensitive approach for detecting patients with high-risk diabetes while optimising the allocation of $\mathrm{HbA1c}$ testing. Implementation of these methods will optimise the usage of resources devoted to the management of diabetes in Trincomalee, Sri Lanka. Further external validation with diverse patient populations is required before applying our algorithm more widely.

\section{BACKGROUND}

The global prevalence of diabetes mellitus has rapidly increased and diabetes is now one of the leading causes of morbidity and mortality worldwide. ${ }^{12}$ This growing epidemic is straining healthcare systems particularly in low- and middle-income countries (LMICs), where physician shortages and technological constraints are endemic. ${ }^{3}{ }^{4}$ Sri Lanka,

\section{Strengths and limitations of this study}

- This study is the first to characterise type 2 diabetes within the population of Trincomalee, Sri Lanka, adding to our collective understanding of populationspecific considerations for managing diabetes worldwide.

- This study's regression models feature populationadjusted haemoglobin A1c ( $\mathrm{HbA1c}$ ) thresholds, time since last oral intake and capillary blood glucose and have predictive value in determining glycaemic control in patients with type 2 diabetes in Trincomalee, Sri Lanka.

- The methodology described in this study can generate models which reduce the need for resource intensive $\mathrm{HbA1C}$ testing in settings where access to testing is limited.

- The study has a small and homogeneous study population which limits the generalisability and predictive value of the described algorithms. Specifically, this study includes only patients with type 2 diabetes who are not insulin dependent and who received care in a community practice setting, which may restrict the widespread use across Sri Lanka.

an island nation southeast of India, presents an example of a LMIC experiencing a high burden of type 2 diabetes, health system congestion and technological shortcomings. Rapid, yet accessible, methods of assessing glycaemia are needed to facilitate diabetes care in such clinical settings.

Several clinically validated methods are routinely employed to assess glycaemic control in patients with type 2 diabetes, including haemoglobin A1c (HbAlc), selfmonitoring of capillary blood glucose (CBG) and assessment of fasting plasma glucose (FPG).$^{5}$ While HbAlc testing is recognised as the standard of care for measuring glycaemic control and is becoming more widely available 
in low- and middle-income settings, patients in Sri Lanka still pay out-of-pocket to obtain HbAlc testing at private laboratory facilities. The World Bank has reported that in 2016, annual per capita healthcare expenditures in Sri Lanka were USD153. HbA1c testing, which costs anywhere between USD22 and USD65 per test, is thus associated with a substantial opportunity cost and most public facilities in rural Sri Lanka lack the financial and human resource capacity to make HbAlc a sustainable marker of glycaemic control. ${ }^{67}$ Since public subsidisation of diabetes focussed supplies and laboratory services are currently limited to a glucometer, monthly glucometer strips and a CBG measurement at regular appointments, CBG remains the most appropriate method of assessing glycaemic control in this population. Previous studies demonstrate significant concordance between HbAlc and CBG: both FPG and post-prandial blood glucose (PPBG) showed strong positive correlations with HbAlc in numerous clinical settings including Sri Lanka. ${ }^{8-12}$ Thus, CBG testing may be an alternative to HbAlc to assess long-term glycaemic control in rural Sri Lanka.

The validity of CBG alone to predict HbAlc is, however, controversial, as predicting changes in HbAlc from changes in CBG is not computationally straightforward. ${ }^{13}$ Linear regression models are frequently used to impute biomarker levels such as HbAlc from data sets that multidimensionally characterise disease. ${ }^{14}{ }^{15}$ Yet heterogeneous population characteristics present major challenges to validating these models in cohorts with uneven parameter distributions. ${ }^{14}$ 15 Cross-validation, where multidimensional data sets are divided into evenly sized subsets to train and test regression models, is a common method for generating and validating clinically useful algorithms. ${ }^{16}$ The results from algorithm validation are, however, subject to replication instability, where differential sampling uncovers large variation in predictive value. ${ }^{1819}$ Despite such shortcomings, regression models may provide a foundation for rapid and accessible assessment of glycaemia in patients with diabetes in Sri Lanka and other LMICs. We report here an alternative method for imputing and interpreting HbA1c from CBG levels within the Tamil population in eastern Sri Lanka that enables providers to rapidly risk-stratify patients with type 2 diabetes, thus reducing the demand for HbAlc testing while ensuring access for high-risk patients.

\section{MATERIALS AND METHODS}

\section{Study subjects}

We previously reported the implementation of a model of care that leverages Tamil and Sinhala-speaking medical assistants to address congestion within healthcare settings in Trincomalee, Sri Lanka. ${ }^{20}$ For the purposes of this study, we expanded the skillsets of the previously trained medical assistants to include study participant recruitment and HbAlc testing. Recruitment was restricted to patients who met eligibility criteria: (1) confirmed history of type 2 diabetes and (2) not taking insulin. Medical histories and medications of all study participants were verified using medical records and all participants provided written informed consent. Data were obtained for 220 participants across three different hospitals: Trincomalee General Hospital, Selvanayagapuram Hospital and Sampaltheevu Hospital.

\section{Patient and public involvement}

Study participants consisted of individuals who met eligibility criteria as outlined above. Public involvement for the research was obtained primarily through informing the Eastern Province Health Minister of the study. Participants were not involved in the recruitment, design, conduct, reporting or dissemination plans. Results will be disseminated via channels approved by the Eastern Province Health Minister and presented at national and international conferences.

\section{Data collection and sampling}

Date of birth, sex, smoking history, duration of diabetes, current diabetes treatment regimen and history of recent hypoglycemic symptoms (nervousness, diaphoresis, tremors and loss of consciousness) were collected for each study participant. Each participant also reported the number of hours since last oral intake other than water. Height, weight, blood pressure and capillary blood specimens were collected from study participants. CBG was measured using a Contour Next Blood Glucose Monitoring System (Bayer), and HbAlc was measured using a DCA Vantage Analyzer (Siemens) imported from the USA, due to local scarcity of HbAlc testing resources. Quality control of both instruments was performed per manufacturers' specifications. The Bayer Contour Next has been shown to have excellent analytical accuracy. ${ }^{21}$ Simple randomisation of the entire study population assigned each participant to either a development cohort $(\mathrm{n}=110)$ or a validation cohort $(n=110)$. The demographic characteristics of each cohort were compared using t-tests, $\chi^{2}$ tests and Fisher's exact tests as appropriate. All analyses were conducted using SAS 9.4 (SAS Institute, Cary, North Carolina) and reported using the TRIPOD (Transparent Reporting of a multivariable prediction model for Individual Prognosis or Diagnosis) reporting guidelines. ${ }^{22}$

\section{Model development and validation}

HbA1c was regressed on each of its potential predictors within the development cohort, including capillary blood glucose, age, sex, body mass index, duration of diabetes and other variables. Capillary blood glucose was the only significant predictor $(p<0.05)$ and was entered in the final model. Participants were stratified by last oral intake to generate models that would account for a patient's fasting state at the time of sample collection. Two different stratifications were performed to account for; (1) postprandial glucose physiology and (2) the observed bimodal distribution in hours since last oral intake, with peaks occurring at 3 hours and 13 hours. The first 
model stratified participants by last oral intake into three groups $(<3$ hours, 3 hours to 8 hours and $>8$ hours since last oral intake) (Model \#1), in line with what is known physiologically about postprandial glucose levels. ${ }^{23}$ The second model stratified participants by last oral intake into two groups $(<8$ hours and $>8$ hours since last oral intake) (Model \#2), in line with the bimodal distribution of last oral intake within the study population. Capillary blood glucose cutoffs were calculated from both models that corresponded to each category of last oral intake (see online supplementary appendix A for equations). These cutoffs were then used to categorise glycaemic control according to estimated HbA1c as follows: 'wellcontrolled' (HbA1c $\leq 7.0 \%)$, 'moderately-controlled' (HbA1c $>7.0$ to $<9.0 \%$ ) and 'poorly-controlled' (HbA1c $\geq 9.0 \%$ ). The predictive value of both models was assessed in the validation cohort by categorising participants by their estimated HbA1c values and their measured HbA1c values and assessing the agreement of the models with the measured HbAlc values. The percent of participants correctly predicted as well as kappa values were calculated as quantitative measures of agreement between models and measured $\mathrm{HbAlc}$ values.

\section{HbA1c testing algorithm}

Model performance was evaluated post-validation to devise a strategy for identifying individuals who require further HbAlc testing. Our method of categorising participants by estimated glycaemic control necessitates minimising dangerous type II errors (underestimating an individual's actual risk). Thus, a new HbAlc threshold was determined from the distribution of estimated HbAlc values of participants who were high-risk but miscategorised as low-risk. This threshold was applied to an algorithm that categorises participants according to whether they require further HbAlc testing. The development cohort and Model \#2 parameters were used to calibrate this algorithm. The predictive value of the recalibrated model was subsequently validated as described above to determine need for further HbAlc testing.

\section{RESULTS}

\section{Model development and validation}

Table 1 describes demographic data for the combined, development and validation cohorts. None of the variables were significantly different between the development data set and the validation data set. Table 2 shows

Table 1 Demographics of combined, development and validation cohorts

\begin{tabular}{|c|c|c|c|c|}
\hline & Combined $(n=220)$ & Development $(n=110)$ & Validation $(n=110)$ & $P$ value \\
\hline Age (years) & $60 \pm 10$ & $59 \pm 10$ & $61 \pm 10$ & 0.3126 \\
\hline Sex & & & & 1.0000 \\
\hline Male & $54(25 \%)$ & $27(25 \%)$ & $27(25 \%)$ & \\
\hline Female & $166(75 \%)$ & $83(75 \%)$ & $83(75 \%)$ & \\
\hline Smoking (yes (\%)) & $5(2 \%)$ & $2(2 \%)$ & $3(3 \%)$ & 0.6510 \\
\hline Duration of DM (years) & $6.5 \pm 5.8$ & $5.9 \pm 5.1$ & $7.1 \pm 6.4$ & 0.1212 \\
\hline Treatment for DM & & & & 0.4713 \\
\hline Diet only & $8(4 \%)$ & $5(5 \%)$ & $3(3 \%)$ & \\
\hline Oral medications & $212(96 \%)$ & $105(95 \%)$ & 107 (97\%) & \\
\hline Metformin & $183(84 \%)$ & $88(80 \%)$ & $95(86 \%)$ & 0.1093 \\
\hline Sulfonylurea & $115(53 \%)$ & $54(49 \%)$ & $61(56 \%)$ & 0.2742 \\
\hline Thiazolidinediones & $5(2 \%)$ & $2(2 \%)$ & $3(3 \%)$ & 0.6803 \\
\hline Dipeptidyl peptidase 4 inhibitors & $1(1 \%)$ & $1(1 \%)$ & $0(0 \%)$ & 1.0000 \\
\hline Hypoglycemic symptoms (Yes (\%)) & $112(51 \%)$ & $57(52 \%)$ & $55(51 \%)$ & 0.8952 \\
\hline $\operatorname{BMI}\left(\mathrm{kg} / \mathrm{m}^{2}\right)$ & $26 \pm 5$ & $26 \pm 5$ & $26 \pm 4$ & 0.9482 \\
\hline Systolic blood pressure $(\mathrm{mm} \mathrm{Hg})$ & $134 \pm 21$ & $133 \pm 20$ & $134 \pm 22$ & 0.2434 \\
\hline Diastolic blood pressure $(\mathrm{mm} \mathrm{Hg})$ & $80 \pm 11$ & $81 \pm 11$ & $80 \pm 11$ & 0.6873 \\
\hline Last oral intake (hours) & $7.8 \pm 5.2$ & $7.8 \pm 5.2$ & $7.9 \pm 5.3$ & 0.8978 \\
\hline Last oral intake & & & & 0.7892 \\
\hline$<3$ hours & $59(27 \%)$ & $29(26 \%)$ & $30(27 \%)$ & 0.8790 \\
\hline$\geq 3$ and $\leq 8$ hours & $42(19 \%)$ & $23(21 \%)$ & $19(17 \%)$ & 0.4926 \\
\hline$>8$ hours & $119(54 \%)$ & $58(53 \%)$ & $61(55 \%)$ & 0.6848 \\
\hline Capillary blood glucose (mg/dL) & $178 \pm 80$ & $170 \pm 83$ & $187 \pm 77$ & 0.1140 \\
\hline $\mathrm{HbA1c}(\%)$ & $8.3 \pm 1.8$ & $8.1 \pm 1.8$ & $8.6 \pm 1.8$ & 0.0634 \\
\hline
\end{tabular}


Table 2 Categorisations of glycaemic control in Model \#1 (left) and Model \#2 (right)

Time since last oral intake

(Model \#1)

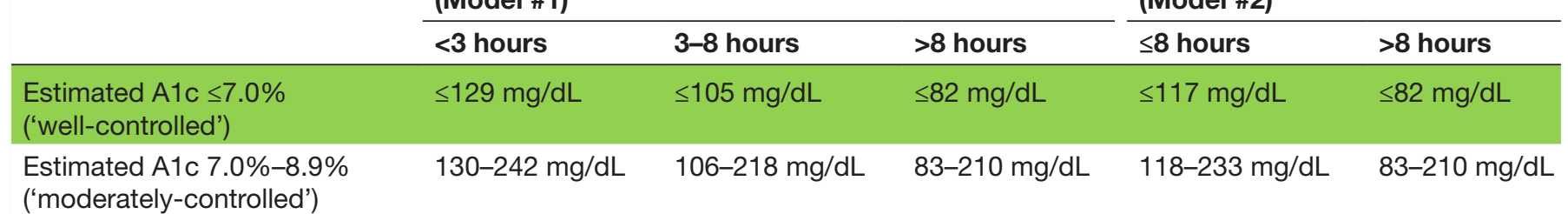

Time since last oral intake (Model \#2) last oral intake parameters and glycaemic control categorisations for Model \#1 and Model \#2. For example, a patient with $\mathrm{CBG} \leq 129 \mathrm{mg} / \mathrm{dL}$ who ate $<3$ hours before testing would be considered 'well-controlled' with an estimated HbA1c $\leq 7.0 \%$ using Model \#1 parameters. These categorisations allow providers to estimate a patient's glycaemic control using only capillary blood glucose and time since last oral intake.

Table 3 show the relationship between actual glycaemic control (categorised by measured HbA1c) and estimated glycaemic control (calculated from the models). Areas highlighted in green represent agreement between the estimated glycaemic control categorisation and the actual glycaemic control categorisation. Areas in white represent disagreement between the estimated glycaemic control categorisation and actual glycaemic control categorisation. In Model \#1, 56.3\% of participants were correctly categorised ( $\kappa=0.2425,95 \%$ CI $(0.0959$ to 0.3890$))$. The $\mathrm{SE}$ and root mean square error values of the regression model are 0.11 and $1.35 \mathrm{HbA1c}$ percentage points, respectively. In Model \#2, 60\% of participants were correctly categorised ( $\kappa=0.2957,95 \%$ CI $(0.1528$ to 0.4386$)$ ). The $\mathrm{SE}$ and root mean square error values of the regression model are 0.11 and $1.40 \mathrm{HbA1c}$ percentage points, respectively. For comparison to other similar models in the literature, we also report the sensitivity and specificity of our models to detect patients whose HbAlc is $\geq 9 \%$; Model \#1 had sensitivity of $50.0 \%$ and specificity of $86.5 \%$ and Model \#2 had a sensitivity of $50.0 \%$ and specificity of $89.2 \%$.

\section{HbA1c testing algorithm}

Online supplementary table S1 (see Appendix B) illustrates the proposed algorithm for identifying individuals who require further HbA1c testing. The algorithm aims to reduce underestimation of risk of inadequate glycaemic control in patients while simultaneously minimising the need for HbA1c testing. Use of this algorithm requires an appropriate HbAlc threshold that minimises both risk underestimation and excessive HbAlc usage. Several potential thresholds were derived from the distribution of estimated HbAlc values among high-risk patients who were incorrectly categorised as low-risk or moderate-risk $(\mathrm{n}=14)$.

Online supplementary table S2 (see Appendix B) demonstrates these thresholds as well as their respective type II error rates (the percentage of patients who were high-risk but not grouped as high-risk nor identified for HbAlc testing by the algorithm) and the percentage of the development cohort that would need to have HbA1c testing if that threshold was selected. The optimal balance between type II error rate and total burden of HbA1c testing is with an estimated HbA1c threshold of $7.4 \%$ (sample type II error rate of $7.1 \%$ while having to perform HbA1c testing on $56.3 \%$ of the sample).

The updated algorithm, recalibrated with this threshold presented in table 4 , was applied to the validation cohort in order to assess its ability to maintain an acceptable type II error rate while reducing the need for HbAlc testing. Table 5 presents the results of this validation. Only one

Table 3 Validation of Model \#1 and Model \#2 through a comparison of agreement between actual glycaemic control categorisations and estimated glycaemic control categorisations

\begin{tabular}{|c|c|c|c|c|c|c|}
\hline & \multicolumn{3}{|c|}{$\begin{array}{l}\text { Model \#1 } \\
\kappa=0.2425,95 \% \mathrm{Cl}(0.0959 \text { to } 0.3890)\end{array}$} & \multicolumn{3}{|c|}{$\begin{array}{l}\text { Model \#2 } \\
\kappa=0.2957,95 \% \mathrm{Cl}(0.1528 \text { to } 0.4386)\end{array}$} \\
\hline & $\begin{array}{l}\text { Measured A1c } \\
\leq 7.0 \%\end{array}$ & $\begin{array}{l}\text { Measured A1c } \\
7.0 \%-8.9 \%\end{array}$ & $\begin{array}{l}\text { Measured A1c } \\
\geq 9.0 \%\end{array}$ & $\begin{array}{l}\text { Measured A1c } \\
\leq 7.0 \%\end{array}$ & $\begin{array}{l}\text { Measured A1c } \\
7.0 \%-8.9 \%\end{array}$ & $\begin{array}{l}\text { Measured A1c } \\
\geq 9.0 \%\end{array}$ \\
\hline $\begin{array}{l}\text { Estimated A1c } \\
\leq 7.0 \%\end{array}$ & 3 & 3 & 1 & 3 & 1 & 1 \\
\hline $\begin{array}{l}\text { Estimated A1c } \\
7.0 \%-8.9 \%\end{array}$ & 17 & 41 & 17 & 17 & 45 & 17 \\
\hline $\begin{array}{l}\text { Estimated A1c } \\
\geq 9.0 \%\end{array}$ & 1 & 9 & 18 & 1 & 7 & 18 \\
\hline
\end{tabular}


Table 4 Algorithm for decision-making regarding $\mathrm{HbA} 1 \mathrm{c}$ testing; updated to reflect chosen $\mathrm{HbA} 1 \mathrm{c}$ threshold value of 7.4

\begin{tabular}{llll}
\hline & If estimated HbA1c $<\mathbf{7 . 4 \%}$ & If estimated HbA1c 7.4\%-8.9\% & If estimated HbA1c $\geq \mathbf{9 . 0} \%$ \\
\hline HbA1c Testing & No HbA1c testing needed & HbA1c testing needed & No HbA1c testing needed \\
Treatment & $\begin{array}{l}\text { Treat as non-high-risk (well-controlled or } \\
\text { moderately-controlled according to eHbA1c) }\end{array}$ & Treat according to HbA1c result & Treat as poorly-controlled \\
& & & \\
\hline
\end{tabular}

eHbA1c, estimated HbA1c; HbA1c, haemoglobin A1c.

high-risk participant out of 36 total high-risk participants would have been placed in the low-risk category and not been identified for further HbAlc testing (type II error rate of $2.8 \%$ ) with a recalibrated HbAlc threshold of $7.4 \%$. From the 110 participants in the validation cohort, 63 were identified for further testing $(57.3 \%)$. Of these, $17(27.0 \%)$ were high-risk participants and $46(73.0 \%)$ were non-high-risk participants. In summary, the algorithm correctly identified $97.2 \%$ of high-risk individuals either by directly identifying them as high-risk or by identifying them for further testing.

\section{DISCUSSION AND CONCLUSIONS}

Methods designed to guide the allocation of resources for diabetes management in LMICs like Sri Lanka are necessary due to physician shortages and inadequate resources for routine HbAlc testing. Through the use of regression models and cross-validation, we present an algorithm that detects high-risk individuals either by directly identifying them using random CBG testing or by flagging them for further HbAlc testing. The algorithm had a sensitivity of $97.2 \%$ while reducing the number of HbAlc tests by about $40 \%$. The algorithm we devised has two main advantages: (1) it minimises type II errors and (2) it is tailored to the characteristics of the patient population. First, by identifying patients in need of further HbA1c testing as well as patients who are estimated to be at high-risk, the algorithm minimises the number of patients who would receive an inadequate level of care. In the setting of Trincomalee, Sri Lanka, where access to HbAlc testing is limited, an HbAlc threshold of $7.4 \%$ cuts down on the demand for HbAlc testing while missing very few high-risk patients with type

Table 5 Application of HbA1c testing decision algorithm to validation group

\begin{tabular}{llcc}
\hline & $\begin{array}{l}\text { Actual A1c } \\
<9.0 \%\end{array}$ & $\begin{array}{l}\text { Actual A1c } \\
\mathbf{2 9 . 0 \%}\end{array}$ & Total \\
\hline $\begin{array}{l}\text { Estimated HbA1c } \\
<7.4 \%\end{array}$ & 21 & 1 & 22 \\
$\begin{array}{l}\text { Estimated HbA1c } \\
7.4 \%-8.9 \%\end{array}$ & 46 & 17 & 63 \\
$\begin{array}{l}\text { Estimated HbA1c } \\
\geq 9.0 \%\end{array}$ & 7 & 18 & 25 \\
Total & 74 & 36 & 110 \\
\hline
\end{tabular}

HbA1c, haemoglobin A1c.
2 diabetes. This recalibrated threshold allows the algorithm to have the lowest type II error rate for this kind of model observed in the literature. Second, because the algorithm was derived from and validated in the ethnic cohort in which it will be applied, its use is fitted for this particular clinical setting. Racial and ethnic differences in HbAlc have been previously documented, though these differences have an unknown impact on the clinical management of diabetes or the incidence of diabetic complications. ${ }^{24-27}$ Furthermore, data concerning HbAlc variation between Sri Lankans and internationally accepted HbA1c standards for glycaemic control are sparse. A model that is built specifically for this group is thus clinically advantageous until more is known about the effects of racial and ethnic variation in HbAlc on the clinical management of diabetes.

Although subject recruitment was conducted in a hospital setting, the distinction between the hospitalderived and community-derived patient populations in Sri Lanka must be highlighted. This study is focussed on community derived study subjects waiting in line for their routine checkups at public hospital-based clinics, not the inpatient population where there is a higher likelihood of finding poor glycaemic control and comorbidities in the patient population. In Sri Lanka, patients without financial means to pay for private community clinics or laboratory testing must visit public institutions or smaller provincial facilities for regular diabetes follow-up appointments. Long lines are common in these hospital settings since the traditional outpatient model that is designed to handle this patient population is lacking. As such, the risk profile and comorbidities of this particular hospital-derived patient population closely resembles the general diabetes patient population which would present to the primary care clinics in the community, allowing our model to be generalisable to this rural context. In selecting our patient population for model development, we did not take pre-existing anaemia or chronic kidney disease (CKD) into consideration. While there is some concern that anaemia and CKD may alter the reliability of HbAlc testing, recent research has suggested that this only occurs in patients with severe anaemia and severe CKD. The HbAlc value is unlikely to be altered in patients with mild-to-moderate anaemia and CKD. ${ }^{28}$ Given that our patient population in this study resembles the general diabetes population, it is unlikely that severe anaemia and CKD is sufficiently prevalent in this population to have seriously impacted our findings. 
Given the small sample size $(n=220)$ and the complex nature of glycaemic control, it is not surprising that only $\sim 60 \%$ of participants were correctly categorised by our models into glycaemic control groups and only 50\% of patients were correctly identified as having poorly controlled diabetes. The goal of these analyses, however, was not necessarily to eliminate the need for HbA1c testing altogether, but rather to maximise the usage of this limited resource. This can be accomplished by combining the models with the HbAlc threshold algorithm. In spite of the somewhat low predictive value, the sensitivity and specificity of these initial models is comparable to similar models in the literature (sensitivity range $64.5 \%$ to $81.8 \%$ and specificity range $58.3 \%$ to $87 \%$ ). ${ }^{929-33}$ Many of these other models are comparing predictive value using an HbA1c cut-off of 7.0\%, so the lower sensitivity demonstrated by our models (HbAlc cut-off of 9\%) is to be expected. A recalibrated algorithm with a threshold of $7.4 \%$, though slightly less stringent than the American Diabetes Association (ADA) guidelines (which state that an HbAlc of $<7 \%$ is a reasonable target for many nonpregnant adults), ensures that physicians devote their time to engage in a patient-centred care model with patients with diabetes who have the poorest glycaemic control. ${ }^{34}$ Indeed, it has been previously suggested that a more appropriate target for glycaemic control may lie between $7 \%$ and $8 \%$ in most patients with type 2 diabetes. ${ }^{35}$ The official recommendation from the Sri Lankan College of Endocrinologists states that an HbAlc of $7.0 \%$ is an acceptable glycaemic target for most patients with diabetes. However, their recommendation allows for glycaemic targets ranging from $6.5 \%$ to $8 \%$ depending on patient comorbidities, age, frequency of hypoglycemic episodes, duration of diabetes, life expectancy and patient motivation. ${ }^{36}$ It has also been demonstrated that individuals with an HbAlc of $<7 \%$ do not greatly benefit from patient-centred care interventions; rather, individuals with an $\mathrm{HbA1c}>8.5 \%$ are more likely to benefit from a more efficient use of limited resources. ${ }^{37}$

It must be noted that our HbAlc threshold of $7.4 \%$ is not a treatment target. Rather, this threshold represents the point at which we can be over $95 \%$ confident that a patient with an estimated HbA1c lower than this value is not hyperglycemic and does not have an $\mathrm{HbAlc} \geq 9 \%$. All patients, whether they have an estimated HbAlc higher or lower than $7.4 \%$, will still have a treatment target in line with what is currently known about HbAlc levels and diabetic complications. ${ }^{38} 39$ It should also be emphasised that participants who were categorised as 'non-high-risk' by this algorithm still continue to receive high-quality care and monitoring from medical personnel specialised in diabetes care. Risk-stratifying patients by glycaemic control addresses the issue of congestion in the Sri Lankan healthcare system and may optimise the amount of time clinicians spend with their patients. The implications of this new clinical paradigm emphasise a patientcentric approach to achieving adequate glycaemic control while meeting personal health goals. Such a paradigm empowers patients to work with their providers to arrive at an individualised treatment plan, a strategy that is strongly recommended by all major guidelines. ${ }^{34540}$

\section{Limitations}

Our study cohort of 220 total participants, which were split into two subsets of 110 participants for cross-validation, is relatively small for the generation of this type of regression model. Further studies that incorporate more participants are necessary to further validate these models and resulting algorithm. Furthermore, the scope of our study was restricted to the Tamil population of Trincomalee. It will be necessary to study additional ethnic groups, including the Sinhalese population, in order to generalise our findings. Moreover, an additional analysis that captures patients managed with insulin would further expand our study and allow for the rapid risk stratification of more patients with type 2 diabetes.

\section{Author affiliations}

${ }^{1}$ University of Michigan Medical School, Ann Arbor, Michigan, United States ${ }^{2}$ Medical Scientist Training Program, University of Michigan, Ann Arbor, Ml, United States

${ }^{3}$ Internal Medicine, Michigan Medicine, Ann Arbor, MI, United States

${ }^{4}$ Huron Gastroenterology Associates, Ypsilanti, Michigan, United States

${ }^{5}$ The Grace Girls' Home, Trincomalee, Sri Lanka

${ }^{6}$ Internal Medicine - Metabolism, Endocrinology, and Diabetes, Michigan Medicine, Ann Arbor, Ml, United States

${ }^{7}$ Selvanayagapuram Hospital, Trincomalee, Sri Lanka

${ }^{8}$ Sampaltheevu Hospital, Trincomalee, Sri Lanka

${ }^{9}$ Trincomalee General Hospital, Trincomalee, Sri Lanka

${ }^{10}$ Clinical Medicine, University of Colombo, Colombo, Western, Sri Lanka

${ }^{11}$ Pathology - Informatics, Michigan Medicine, Ann Arbor, Michigan, United States

${ }^{12}$ School of Public Health, University of Michigan, Ann Arbor, MI, United States

Acknowledgements We would like to thank Heather Stites and Beth Gibson for facilitating communication between authors. Many thanks to Ruvan Wickramasinghe for contributions to project conception and logistical support on sight.

Contributors All authors made significant contributions to the manuscript. MC and GEH are equal contributors. WHH and AKS are equal contributors. MC, GEH, WHH and AKS conceived the study, collected and curated data, performed data analysis, interpreted results and wrote the manuscript. SD helped write the manuscript. LM helped with data analysis. NG and JW provided logistical support and coordinated personnel to facilitate data collection. TJ, AS, and GB facilitated data collection. PK helped interpret results and coordinated personnel to facilitate data collection. UB provided equipment and reagents necessary for data collection and helped interpret results. All authors revised the manuscript for intellectual content. All authors have contributed to and read the manuscript and approved the final copy. We certify that this manuscript is not under review by any other journal.

Funding The authors would like to acknowledge support received from the National Institute of Diabetes and Digestive and Kidney Diseases (NIDDK), the National Cancer Institute (NCI) (F30-CA-210379), the Michigan Diabetes Research Center, the William Davidson Institute and VeAhavta.

Competing interests None declared.

Patient consent for publication Not required.

Ethics approval All procedures performed in studies involving human participants were in accordance with the ethical standards of the institutional and/or national research committee and with the 1964 Helsinki declaration and its later amendments or comparable ethical standards. Informed consent was obtained from all individual participants included in the study. The University of Michigan Institutional Review Board (IRB) and the Provincial Department of Health Services of the Eastern Province in Sri Lanka reviewed the study (HUM00126960) and determined that it meets criteria for a Quality Assurance/Quality Improvement 
initiative aimed at improving pre-existing healthcare delivery. The study was thus deemed outside of the regulatory jurisdiction of the IRB and a waiver was provided.

Provenance and peer review Not commissioned; externally peer reviewed.

Data availability statement Data are available upon reasonable request. The de-identified data sets used and/or analysed for this study are available from the corresponding authors on request (wherman@med.umich.edu and aksaha@med. umich.edu).

Open access This is an open access article distributed in accordance with the Creative Commons Attribution Non Commercial (CC BY-NC 4.0) license, which permits others to distribute, remix, adapt, build upon this work non-commercially, and license their derivative works on different terms, provided the original work is properly cited, appropriate credit is given, any changes made indicated, and the use is non-commercial. See: http://creativecommons.org/licenses/by-nc/4.0/.

\section{ORCID iD}

Anjan K. Saha http://orcid.org/0000-0001-6721-1599

\section{REFERENCES}

1 Diabetes. Available: https://www.who.int/news-room/fact-sheets/ detail/diabetes [Accessed 24 Apr 2019].

2 IDF Diabetes Atlas - Home. Available: https://www.diabetesatlas.org/ [Accessed 24 Apr 2019].

3 Bonair A, Rosenfield P, Tengvald K. Medical technologies in developing countries: issues of technology development, transfer, diffusion and use. Soc Sci Med 1989;28:769-81.

4 De Silva AP, Liyanage IK, De Silva STG, et al. Migration of Sri Lankan medical specialists. Hum Resour Health 2013;11:21.

5 Sacks DB, Arnold M, Bakris GL, et al. Guidelines and recommendations for laboratory analysis in the diagnosis and management of diabetes mellitus. Diabetes Care 2011;34:e61-99.

6 Katulanda GW, Katulanda P, Dematapitiya C, et al. Plasma glucose in screening for diabetes and pre-diabetes: how much is too much? analysis of fasting plasma glucose and oral glucose tolerance test in Sri Lankans. BMC Endocr Disord 2019;19:11.

7 Arrendale JR, Cherian SE, Zineh I, et al. Assessment of glycated hemoglobin using $\mathrm{A} 1 \mathrm{CNow}+$ point-of-care device as compared to central laboratory testing. J Diabetes Sci Technol 2008;2:822-8.

8 Malavige GN, Weerasooriya N, de Alwis NMW, et al. The validity of fasting blood glucose and post-prandial blood glucose measurement as an index of glycaemic control in Sri Lankan patients with type 2 diabetes. Ceylon Med J 2006;51:40-1.

9 Al-Lawati JA, Al-Lawati AM. The utility of fasting plasma glucose in predicting glycosylated hemoglobin in type 2 diabetes. Ann Saudi Med 2007;27:347-51.

10 Makulo JR, Nseka NM, Lepira FB, et al. [Correlation between capillary fasting glucose and $\mathrm{HbA} 1 \mathrm{c}$ : study on 181 type 2 diabetics patients in Democratic Republic of the Congo]. Med Trop 2010;70:513-6.

11 Ketema EB, Kibret KT. Correlation of fasting and postprandial plasma glucose with $\mathrm{HbA1c}$ in assessing glycemic control; systematic review and meta-analysis. Arch Public Health 2015;73:43.

12 Herath HMM, Weerarathna TP, Fonseka CL, et al. Targeting postprandial blood sugar over fasting blood sugar: a clinic based comparative study. Diabetes Metab Syndr 2017;11:133-6.

13 Bouma M, Dekker JH, de Sonnaville JJ, et al. How valid is fasting plasma glucose as a parameter of glycemic control in non-insulinusing patients with type 2 diabetes? Diabetes Care 1999;22:904-7.

14 Masconi KL, Matsha TE, Echouffo-Tcheugui JB, et al. Reporting and handling of missing data in predictive research for prevalent undiagnosed type 2 diabetes mellitus: a systematic review. Epma $J$ 2015;6:7.

15 Kengne AP, Masconi K, Mbanya VN, et al. Risk predictive modelling for diabetes and cardiovascular disease. Crit Rev Clin Lab Sci 2014:51:1-12.

16 Snee RD. Validation of regression models: methods and examples. Technometrics 1977;19:415-28.

17 Picard RR, Berk KN. Data splitting. Am Stat 1990;44:140-7.

18 Moons KGM, Kengne AP, Woodward M, et al. Risk prediction models: I. Development, internal validation, and assessing the incremental value of a new (bio)marker. Heart 2012;98:683-90.
19 Steyerberg EW, Harrell FE, Borsboom GJ, et al. Internal validation of predictive models: efficiency of some procedures for logistic regression analysis. J Clin Epidemiol 2001;54:774-81.

20 Saha AK, Gunaratnam N, Patil R, et al. A new model for diabetesfocused capacity building - lessons from Sri Lanka. Clin Diabetes Endocrinol 2018;4:22.

21 Klonoff DC, Parkes JL, Kovatchev BP, et al. Investigation of the accuracy of 18 marketed blood glucose monitors. Diabetes Care 2018;41:1681-8.

22 Moons KGM, Altman DG, Reitsma JB, et al. Transparent reporting of a multivariable prediction model for individual prognosis or diagnosis (TRIPOD): explanation and elaboration. Ann Intern Med 2015;162:W1-73.

23 American Diabetes Association. Postprandial blood glucose. American diabetes association. Diabetes Care 2001;24:775-8.

24 Herman WH, Cohen RM. Racial and ethnic differences in the relationship between $\mathrm{HbA} 1 \mathrm{c}$ and blood glucose: implications for the diagnosis of diabetes. J Clin Endocrinol Metab 2012;97:1067-72.

25 Selvin E, Steffes MW, Ballantyne CM, et al. Racial differences in glycemic markers: a cross-sectional analysis of community-based data. Ann Intern Med 2011;154:303-9.

26 Mostafa SA, Davies MJ, Webb DR, et al. Independent effect of ethnicity on glycemia in South Asians and white Europeans. Diabetes Care 2012;35:1746-8.

27 Kehl KG, Findeisen HM, Fardo DW, et al. Race-ethnicity as an effect modifier of the association between $\mathrm{HbAlc}$ and mortality in U.S. adults without diagnosed diabetes. Eur J Endocrinol 2011;165:275-81.

28 Borg R, Persson F, Siersma V, et al. Interpretation of $\mathrm{HbA}_{1 \mathrm{c}}$ in primary care and potential influence of anaemia and chronic kidney disease: an analysis from the Copenhagen Primary Care Laboratory (CopLab) Database. Diabet Med 2018;35:1700-6.

29 Rosediani M, Azidah AK, Mafauzy M. Correlation between fasting plasma glucose, post prandial glucose and glycated haemoglobin and fructosamine. Med J Malaysia 2006;61:67-71.

30 Swetha DS. Comparison of fasting blood glucose \& post prandial blood glucose with $\mathrm{HbA} 1 \mathrm{c}$ in assessing the glycemic control. Int $J$ Healthc Biomed Res 2014;2:134-9.

31 Datta S, Pal M, Mitra R, et al. Value of assessing postprandial and rasting plasma glucose as a surrogate for glycated hemoglobin in diabetic glycemic control. World J Pharm Res 2014;3:494-503.

32 Avignon A, Radauceanu A, Monnier L. Nonfasting plasma glucose is a better marker of diabetic control than fasting plasma glucose in type 2 diabetes. Diabetes Care 1997;20:1822-6.

33 Otieno FCF, Ng'ang'a L, Kariuki M. Validity of random blood glucose as a predictor of the quality of glycaemic control by glycated haemoglobin in out-patient diabetic patients at Kenyatta national Hospital. East Afr Med J 2002;79:491-5.

34 American Diabetes Association. 6. Glycemic Targets: Standards of Medical Care in Diabetes-2019. Diabetes Care 2019;42:S61-70.

35 Qaseem A, Wilt TJ, Kansagara D, et al. Hemoglobin A1c targets for glycemic control with pharmacologic therapy for nonpregnant adults with type 2 diabetes mellitus: a guidance statement update from the American College of physicians. Ann Intern Med 2018;168:569-76.

36 Diabetes mellitus management guidelines, 2018. Available: http:// shri.lk/wp-content/uploads/2019/03/diabetes-guidelines.pdf

37 Slingerland AS, Herman WH, Redekop WK, et al. Stratified patientcentered care in type 2 diabetes: a cluster-randomized, controlled clinical trial of effectiveness and cost-effectiveness. Diabetes Care 2013;36:3054-61.

38 Rohlfing CL, Wiedmeyer H-M, Little RR, et al. Defining the relationship between plasma glucose and $\mathrm{HbA}(1 \mathrm{c})$ : analysis of glucose profiles and $\mathrm{HbA}(1 \mathrm{c})$ in the Diabetes Control and Complications Trial. Diabetes Care 2002;25:275-8.

39 Davidson JA. Treatment of the patient with diabetes: importance of maintaining target $\mathrm{HbA}(1 \mathrm{c})$ levels. Curr Med Res Opin 2004;20:1919-27.

40 Handelsman Y, Bloomgarden ZT, Grunberger G, et al. American association of clinical endocrinologists and american college of endocrinology - clinical practice guidelines for developing a diabetes mellitus comprehensive care plan - 2015. Endocr Pract 2015;21 Suppl 1:1-87. 